\title{
EL MUSEO BELLO DE PUEBLA
}

\section{Por José Miguel Quintana}

El 5 de septiembre de 1938 falleció en la ciudad de Puebla, el señor José Mariano Bello y Acedo propietario de un magnífico museo integrado con pinturas, esculturas, loza blanca o talavera de Puebla, herrajes, lacas, muebles, plata, vidrios y cristales, tapices, cobres, objetos religiosos, instrumentos musicales y en fin, cuanto de buen gusto y arte es posible coleccionar, proveniente en gran parte de viejas casas poblanas.

Esta galería originalmente se formó con la cuarta parte de la que a su vez tuvo el señor José Luis Bello y González, padre de José Mariano Bello, pero que éste acrecentó considerablemente, dada su afición y amplios recursos pecuniarios.

Don José Mariano Bello no llegó a inventariar su colección, lo que hubiera sido muy útil en todo momento, y sólo se conocen al detalle los objetos religiosos que posefa por el inventario que hizo la Dirección de Bienes Nacionales de la Secretaria de Hacienda, con motivo de su incautación temporal y posterior devolución el 19 de agosto de 1935 (Anexo 1).

El 24 de diciembre de 1918 el señor José Mariano Bello otorgó en Puebla testamento público cerrado, del cual es de interés la cláusula cuarta que dice: "Que la galería de pinturas y obras de arte, después de la muerte de la señora mi esposa, pase en propiedad a la Academia de Educación y Bellas Artes del Estado; cuidando la persona a la que incumba ejecutar esta determinación, de que se acuerde y ordene tódo lo que sea necesario para que no se enajene ni disponga de ninguna de las pinturas, ni de las obras de arte, sino que todo se conserve en recuerdo perdurable del señor mi padre don José Luis Bello, que fue el fundador de esta galería. Los cuadros pintados por mi, que hay en la galería, serán distribuidos o regalados a las personas que deje designadas mi señora."

A pesar de una disposición tan expresa, fueron sustraidos de la colección muchos de los mejores objetos, con múltiples pretextos, por lo que al recibirla el gobierno del Estado, distaba bastante de lo que fue.

En el Periódico Oficial del Estado de Puebla de fecha 28 de marzo de 1944 fue publicada la Ley Orgánica del Mureo José Luis Bello y Gonzdlez, que creó el Museo como institución pública y con plena capacidad juridica, con la finalidad, entre otras, de conservar las colecciones 
artísticas donadas a la Academia de Bellas Airtes de Puebla por el filántropo José Mariano Bello.

Por la misma época, el 19 de febrero de 1944, se habia constituido, a sugestión del señor Manuel Toussaint, la "Sociedad de Amigos de Puebla", integrada por personas interesadas en la conservación de esa ciudad, y de la cual fue presidente el doctor Toussaint y entusiastas representantes en Puebla los señores Jose Luis Bello y Zetina y licenciado Gustavo Ariza.

En junio de 1944, el licenciado Ariza sugirió al entonces gobernador constitucional del Estado de Puebla, doctor Gonzalo Bautista, la conveniencia de ofr la opinión de personas calificadas para reorganizar el Museo Bello, pronto a inaugurarse. Se pensó en varias personas y, finalmente el 28 de dicho mes, el doctor Bautista invitó por carta a los señores: Manuel Toussaint, Rafael García Granados, Manuel Sánchez Sarto, John Mc. Andrew, Justino Fernández y José Miguel Quintana, este último como coordinador, para ayudar a guiar a su personal en la empresa de organizarlo y de sugerir al gobierno del Estado las medidas adecuadas para su mejor funcionamiento.

El 8 y 9 de julio las personas antes mencionadas se trasladaron a Puebla donde fueron recibidas y atendidas por los señores doctor Salvador Fidel Ibarra, director del Museo, José Luis Bello y Zetina y licenciado Gustavo Ariza.

Como resultado de la visita, se presentó el 20 de julio un informe que ahora después de veinticuatro años se publica, por considerarse de interés para la historia artística de Puebla (Anexo 2).

El 21 de julio de 1944 y con la presencia del señor gobernador, doctor Gonzalo Bautista, fue inaugurado solemnemente el Museo Bello, dirigiendo unas palabras su director, doctor Salvador Fidel Ibarra y dando una breve noticia histórica de la colección el señor José Luis Bello (Anexo 3).

llustramos esta información con un retrato de los cuatro hijos del señor José Luis Bello y González que heredaron por partes iguales su colección: señores Carlos, Rodolfo, Francisco y José Mariano Bello; fotografía tomada en casa del señor Rodolfo Bello por el señor Carlos Alonso Miyar. Se publica también la fotografía de los integrantes de la Comisión: licenciado Gustavo Ariza, doctor Salvador Fidel Ibarra, doctor Justino Fernández, profesor Rafael Garcia Granados, don José Luis Bello y Zetina, profesor John Mc. Andrew, doctor Manuel Toussaint, 
doctor Manuel Sánchez Sarto y licenciado José Miguel Quintana, tomada esta fotografía en los corredores del Museo Bello.

Con objeto de que quien se interese por la Colección Bello, pueda ampliar su investigación, se proporciona una bibliografía suscinta de la misma (Anexo 4).

\section{ANEXO I}

El C. Arq. José Garcia Preciat, Subdirector Int. de Bienes Nacionales,

\section{CERTIFICA}

que en el expediente $210(724.7) /-18570$ del archivo de esta propia Dirección, existe un documento que a la letra dice:

INVENTARIo de los objetos de carácter religioso que con esta fecha se entregan al señor Mariano Bello, domiciliado en la ciudad de Puebla, como depositario y de acuerdo con los términos del acta que con esta misma fecha se levanta.

Ne de orden

Descripcion

Valor

1.- 8 Ramilletes cobre forjado repujados cincelados y dorados a fuego de Mts. 1.48 de altura cada uno considerando que el oro empleado para el dorado de dichas piezas es la cantidad aproximada de 2,800 kls., en ley de 21 kilates a razón de $\$ 3.15$ gramo y agregando a esto el valor artístico de trabajo calculado a razón de $\$ \mathbf{4 0 0 . 0 0}$ cada pieza .

$12,020.00$

2.- 6 Candeleros grandes cobre, forjado, repujados y dorados a fuego de Mts. $1.030 \mathrm{~mm}$. de altura cada uno, considerando que el oro empleado para el dorado de dichas piezas es la cantidad de $3,600 \mathrm{Ks}$. aproximadamente, a razón de $\$ 3.15$ gmo. y agregando a esto el valor artístico de trabajo, calculado a razón de $\$ 400.00$ cada pieza. . . . . .

$\$ 13,740.00$

3.- 4 Candeleros medianos, cobre forjado, cincelados y dorados a fuego, de 0.62 .5 cmts. de altura cada uno, considerando que el oro empleado para el dorado de dichas piezas es la cantidad aproximada de $K .0 .800$ gms., a razón de $\$ \$ .15$ y agregando a éste el valor artístico del trabajo calculando a razón de $\$ 250.00$ cada pieza 
4.- 1 Custodia plata repujada, cincelada y dorada a fuego, de 1.12 ctms. de altura, peso bruto 16 kilos plata, a razón de $\$ 53.00$ kilo que arroja la cantidad de $\$ 48.00$ que unida a la cantidad de $\$ 945.00$ valor aproximado de 0.300 gms. oro a razón de $\$ 3.15$ gmo. y la apreciación artística calculada en la cantidad de $\$ 3,207.00$ hacen un total de.

5.- 1 Crucifijo cobre dorado con cruz y peana madera con cantoneras e I.N.R. de plata

$\$ \quad 400.00$

6. - 1 Custodia teniendo por base un cáliz plata repujada y cincelada, con un peso total de kls. 2 .

$\$ \quad 250.00$

7.- 1 Copón con tapa y patena plata dorada, forjada y cincelada con peso total de kls. 1,500 aproximadamente

8. - 1 Cáliz sin patena, plata forjada y cincelada con aplicaciones de 6 campanitas del mismo material con peso total de kls. 1,600

$\$ \quad 150.00$

9.- 1 Cáliz sin patena, plata forjada, cincelada, dorada, con peso de kls. 0.700

$\$ \quad 300.00$

10. - 1 Cáliz sin patena, plata forjada y dorada, con aplicaciones filigrana del mismo material con peso total de kls. 0.400 estilo Luis XV . . . .

$\$ \quad 100.00$

11. - 2 Candeleros plata repujada, cincelada, con aplica.
ciones del mismo metal con peso total de kls. 1.750 .
12. - 1 Cáliz plata forjada, cincelado con el vaso dorado

11. - 2 Candeleros plata repujada, cincelada, con aplica.
ciones del mismo metal con peso total de kls. 1.750 .
12. - 1 Cáliz plata forjada, cincelado con el vaso dorado en el interior, con peso de kls. 0.300 . . . .

13.- 1 Relicario plata forjado cincelado con aplicaciones cristal con peso de kls. 0.200 falto de un adorno.

14. - 1 Naveta plata forjada calada y cincelada . . .

200.00

50.00

15. - 1 Vinajera compuesta de dos jarritas y platillo plata forjada y cincelada con partes doradas . . . .

16. - 1 Vinajera compuesta de dos jarritas y platillo plata forjada . . . . . . . . . . . . .

17. 4 Medallones plata forjada cincelada con partes doradas con peso total de kls. 1.350

400.00

800.00

80.00

200.00

60.00

30.00

600.00 
18.- 2 Medallones plata repujada cincelada labrada, con partes doradas con peso total de kls. 1.00 . . . \$ $\$ 400.00$

19.- 1 Plato plata con crucifijo en el centro, del mismo metal, forjado y cincelado . . . . . . .

$\$ 200.00$

20.- 2 Navetas; una forjada cincelada plata y la otra plata grabada con cucharillas . . . . . . \$ 50.00

21.- 1 Caja plata repujada para ostias . . . . . . . $\$ 50.00$

22.- 1 Caja madera aplicaciones plata forjada cincelada y calada forrada del interior con terciopelo genovés

23.- 1 Relieve plata repujado

24.- 1 Acetre plata forjada sin hizopo con el interior de zinc con peso de kls. 1.800 . . . . . .

25. 2 Candeleros plata forjada, uno de ellos roto y compuesto, con peso de kls. 1.900 aproximadamente.

26.- 1 Incensario plata forjada y cincelada con depósito interior de cobre, con peso aproximado de kls. 0.700

27.- 2 Atriles madera forrados de terciopelo genovés, con aplicaciones plata repujada, cincelada, con partes doradas . . . . . . . . . . . .

28. - 1 Custodia cobre dorado a fuego con aplicaciones espejos y aplicaciones del mismo metal, cinceladas, con relicario al centro vidrios biselados.

$\$ 1,000.00$

85. - 1 Blandón madera tallada y dorada con pantalla seda con aplicaciones plata repujada, cincelada con partes doradas.

$\$ 700.00$

86.- 2 Repizas pasta o madera imitación talla dorados y rotos algunos adornos

$\$ 10,000.00$

87. - 1 Paño de púlpito, toledano bordado hilo de plata, plata dorada, seda y lentejuelas de oro

88.- 1 Cruz alta con bastón cobre plateado forjado y cincelado

$\$ \quad 250.00$

89. - 2 Faroles plata con bastones cobre forjado y cincelado 
90.- 3 Telas bordadas de ambos lados con imágenes y aplicaciones terciopelo seda e hilo de plata y plata dorada

$\$ 2,000.00$

91. - 1 Manto género seda color blanco bordado sedas colores e hilo plateado . . . . . . . .

92. - I Manto tisú bordado hilo de plata con sedas colores y encaje de plata.

$\$ 2,500.00$

$\$ 2,500.00$

93.- 1 Manto tisú fondo azul plúmbago bordado a tiras seda colores.

$\$ 4,000.00$

94.- 3 Portacorridas madera tallada y dorada . . . . $\$ 450.00$

95.- 2 Esculturas madera policromadas y estofadas . . \$ $\$ 700.00$

96.- 2 Esculturas madera policromada y estofada, San Francisco y Santo Domingo, este último con resplandor y estandarte plata, plata dorada y oro.

$\$ 800.00$

97.- 2 Fragmentos de telas bordadas a colores antiguos, aproximadamente siglo $\mathrm{xvI}$, con marcos madera tallada y dorada

$\$ 1,000.00$

98.- 1 Atril platón cincelado . . . . . . . . . . . . $\$ 60.00$

100.- I Escultura madera policromada y estofada, Virgen con el Niño y ángeles

101.- 1 Imagen Virgen del Rosario madera y armazón tela y cartón con vestidura y manto tela bordada seda e hilo de plata dorada; con toca seda encarnada de perlitas y perlas con adornos oro y piedras de color falsas montadas en oro; con corona con esmeraldas y cristal de roca, con corte de tabla y coronitas de oro y esmeralditas y rosario perlitas en engarce oro y cruz con falsos verdes .

$\$ 3,000.00$

102.- I Manto terciopelo labrado azul cobalto bordado de hilo de plata dorada con cerco de encaje de hilo de plata dorada.

103.- 2 Mantos chicos de tisú hilo de plata dorada, fondos damasco y terciopelo azul con orla de hilo plata dorada

$\$ 6,000.00$

$\$ 1,000.00$

104. - 1 Casulla y paño de cáliz toledano bordado en sedas de colores e hilo de plata dorada y aplicaciones galón plata dorada. 
105. - 1 Casulla y paño de cáliz terciopelo rojo bordado hilo plata dorada . . . . . . . . . .

106. - 1 Casulla y paño de cáliz raso blanco bordado hilo plata dorada con aplicaciones plata dorada . . \$1,900.00

107.- I Capa pluvial con capillo bordado plata y sedas de colores con aplicación galón dorado . . . . . \$8,000.00

108. - 2 Dalmáticas bordadas hilo de plata y seda policromada con orla y aplicaciones, galón plata dorada.

$\$ 5,000.00$

109. - 1 Casulla con paño de cáliz bordado hilo de plata, plata dorada y sedas de colores.

$\$ 1,500.00$

110.- 1 Casulla y paño de cáliz fondo seda crema con aplicaciones terciopelo rojo, bordado con hilo de plata dorada y orlado con galón plata dorada.

$\$ \quad 600.00$

2 Atriles de coro, de pie, madera fina con aplicaciones terciopelo rojo y metal dorado . . . . \$1,000.00

1 Atril madera fina con incrustaciones de madera. $\$ 500.00$

México, D. F., a 19 de agosto de 1935

Recibi.-J. Mariano Bello.-Firmado.-Entregamos por la DirecciónGeneral de Bienes Nacionales.-Fl Inspector de 3/a. J. M. Espinosa Praslow.-Firmado.-En Enc. del Museo de Arte Religioso.-Alfonso Vázquez.-Firmado.-Intervenimos por la Dirección General de Bienes Nacionales.-El Jefe de la Oficina.-Héctor M. Escalona.-Firmado.-El Jefe de la Oficina.-Lic. Armando de Ceballos.-Firmado.-Intervine por la Oficina Central de Inspección Fiscal.-El Inspector de 7/a. José Sánchez Calderón.-Firmado.-Al margen inferior izquierdo un sello con el Escudo Nacional que dice: Estados Unidos Mexicanos. Secretaría de Hacienda y Crédito Público.-Inspección Fiscal.-Emergencia $\mathrm{N}^{\circ} 2$.

Es copia fiel sacada de su original que se coteja en México Distrito Federal, a los veinte dias del mes de julio de mil novecientos cuarenta y cuatro, para ser enviada a la Sociedad de Amigos de Puebla, con domicilio en la casa núm. 28 de la calle de San Ildefonso, en esta ciudad.

José Garcia Preciat.-Firmado 


\section{ANEXo 2}

México, D. F., a 20 de julio de 1944.

Sr. Dr. Gonzalo Bautista,

Gobernador Constitucional del Estado.

Puebla, Pue.

Muy señor nuestro:

Los que suscriben, deferiendo a su atenta invitación para colaborar en la reorganización del Museo "José Luis Bello y González", formado con la colección donada a esa Entidad por don José Mariano Bello, rinden a continuación su informe respecto de las medidas indispensables y necesarias para que dicho Museo, nueva institución cultural poblana, rinda sus mejores frutos.

Después de un minucioso recorrido por los diversos salones de la colección Bello, atendidos por el C. Director Dr. Salvador Fidel Ibarra y por los señores José Luis Bello y Licenciado Gustavo Ariza llegamos a las conclusiones generales siguientes:

I. Es indispensable crear un Patronato General de Museos de la Ciudad de Puebla, en los cuales queden comprendidos el propio Museo Bello, la Academia de Bellas Artes, el Museo del Alfeñique y el Museo de Cerámica de Santa Rosa, con el fin de que, en una forma congruente, se presenten a los visitantes las riquezas que obran en cada una de estas colecciones, y sea posible organizarlos bajo un solo patronato.

II. Es indispensable que se practique una investigación rigurosa para determinar si los objetos del Museo Bello que recibió el Estado son todos los que integraban dicha colección a la muerte de don José Mariano Bello, pues se nota la ausencia de varios de los objetos principales; para esto, no habiéndose formado catálogo en vida del señor Bello, puede facilitarse la investigación con fotografias que obran en poder de particulares, con reseñas sobre la colección, publicadas por personas de reconocida solvencia en periódicos y revistas y con el testimonio de personas, y en cuanto a los objetos religiosos, con el inventario que obra en la Dirección de Bienes Nacionales de los objetos que fueron recogidos al coleccionista por el Gobierno Federal y posteriormente devueltos.

III. Antes de que se intente la reacomodación de los objetos, que, como se verá más adelante, no se hallan expuestos en la forma más adecuada, sería conveniente que el Estado acondicionase el último piso de la casa en que se encuentra el Museo, con el fin de descongestionar los actuales salones, hacer bodegas para objetos que no merecen una constante exhibición, y crear una pequeña biblioteca y una sala de conferencias, así como un despacho para la Sociedad de Amigos de Puebla. 
IV. Dada la diversidad de objetos de distintas épocas y para presentar conjuntos armónicos es conveniente hacer una nueva distribución, para formar, entre otros, un salón neo-clásico, otro de grabados y, uno más, romántico.

V. Para que los objetos puedan ser presentados al público es necesario acondicionar los salones en la forma que se indicará, a continuación, particularmente para cada uno de ellos.

VI. Se sugiere la conveniencia de que cuanto antes se proceda al inventario de todos los objetos del Museo, y a su catalogación selectiva y razonada, que deben hacer especialistas en cada materia. Este catálogo, ilustrado, debe publicarse y ponerse a la venta.

Vistas las anteriores consideraciones se pasa a informar lo que en detalle debe hacerse en cada uno de los grupos de objetos que forman la colección. Bello.

\section{DESPACHO ROJO}

I. Substituir la mesa central por el escritorio de carey incrustado de concha y plata que existía en ese lugar, y que puede fácilmente localizarse por las diversas fotografias que hay de ese recinto, en el que figura la referida pieza.

II. Substituir el actual retrato fotográfico de don José Mariano Bello por otro al óleo, a fin de que no desentone en el conjunto del salón.

III. Corregir el alumbrado defectuoso que tiene este salón.

IV. Cambiar el tapizado de algunos muebles armonizándolo con el de los restantes.

V. Tomar medidas de protección para que el acceso de los visitantes no deteriore el alfombrado actual.

\section{SALÓN DE ROPEROS}

I. Se recomienda colocar la colección de herrajes en este salón, acondicionándolo con un lambrín de madera en el que pueden exhibirse las piezas, además del uso de las vitrinas que ya tiene esta colección.

II. Procurar acomodar los diversos roperos y mesas existentes en este salón en otros; algunos pueden destinarse a amueblar las mismas oficinas del Museo.

Cabe hacer mención especial de una de las mesas de mármol la que está frente a la entrada, a la cual debe buscarse un emplazamiento adecuado, por ser una magnífica pieza florentina del siglo xvir. 


\section{ANTIGUO SALÓN DE hERRA JES}

I. Debe retirarse el cuadro del Padre Carrasco que ocupa el panel central de uno de los muros, buscándole un lugar donde pueda lucir convenientemente, sin desentonar del conjunto del salón respectivo.

II. Las piezas arqueológicas deben de colocarse en uno de los roperos que hay en el Salón de Roperos antes aludido, con cristal en el frente, para que puedan contemplarse holgadamente; estas piezas desentonan en el sitio en que ahora se encuentran.

\section{SaLón de talavera de puebla}

I. Para que puedan lucir las piezas de Talavera es indispensable colocarlas en vitrinas adosadas a las ventanas, sugiriéndose que dichas vitrinas tengan una altura de $1.50 \mathrm{~m}$.; el frente $\mathrm{y}$ las divisiones intermedias deberán ser de cristal.

II. Que se haga una severa selección y, posteriormente, se clasifiquen las piezas de Talavera.

III. Que las vitrinas actuales que no presentan buena visibilidad se desmonten o se aprovechen en alguna otra forma; los azulejos que actualmente forman parte decorativa de las vitrinas de hierro se colocarán en tableros, procurando que dichas piezas puedan ser fácilmente desmontadas, para su estudio por los especialistas, previa autorización expresa del Director del Museo.

IV. Se sugiere la conveniencia de quitar la lámpara que tiene este salón, también decorada con piezas de Talavera, reintegrando éstas a su forma primitiva y disponiéndolas en la misma forma aludida en el párrafo anterior. No es conveniente que en un Museo de esta categoría se ofrezca una pieza arbitraria que pudiera ser objeto de indebidas imitaciones.

\section{SALÓN DE LACAS}

Dada la importancia que tienen las piezas de laca que se exhiben en este salón, se considera conveniente retirar los demás objetos que no son de esa técnica, tales como diversas telas y un ciprés; una vez trasladados esos objetos últimamente aludidos, es conveniente hacer una mejor distribución de las piezas, a efecto de facilitar su estudio.

\section{SALÓN DE PINTURAS}

I. Se sugiere la conveniencia de que se haga un riguroso estudio y selección de los cuadros existentes en el salón, procurando que, preferente, quede en él la pintura europea, y en lo posible sólo obras de reconocido mérito. 
II. Para facilidad de los visitantes deben retirarse los diversos muebles y objetos que hay en el Salón dejando libre la parte central y agrupando los objetos de cristal y de porcelana en otros salones.

III. Deberá procurarse que en este salón se coloque un mobiliario sencillo y adecuado.

SALÓN DE MÚSICA

Con el fin de mejorar el aspecto general de este salón y descongestionarlo se sugiere:

I. Quitar los pergaminos y bustos, sin valor alguno, que hay en las paredes.

II. Retirar el piano vitrina que no presenta ningún interés histórico ni artistico.

III. Amueblar este salón en forma adecuada.

SALON DE ARTE RELIGIOSO

I. Se sugiere la conveniencia de instalar vitrinas con dos gradas, para que en cada una de ellas puedan exhibirse 4 ornamentos, en forma tal que queden debidamente protegidas estas piezas.

II. Debe procederse a un estudio y selección de los objetos de plata.

III. Las alacenas en las cuales se guardan objetos de plata deben forrarse con terciopelo morado en el fondo; los entrepaños deben ser de cristal; detrás de las puertas es conveniente colocar un cierre de cristal, y finalmente hacerles una instalación interior de luz, para que puedan verse mejor los objetos exhibidos.

SALÓN DE CRISTAL

I. Se sugiere la instalación de vitrinas en los vanos de los balcones, a efecto de que puedan contemplarse a contraluz las piezas de cristal que se exhiben en ese salón; las vitrinas pueden ser semejantes a la que se recomiendan para el Salón de Talavera.

SALÓN DE LOZA CHINA Y PORGELANAS

I. En el actual salón de loza china es indispensable pintar a un solo tono claro paredes y techo; deben concentrarse en éste las piezas semejantes que haya en otros salones.

II. Se sugiere la conveniencia de retirar las pinturas que se exhiben ahora en ese salón, a fin de no restar importancia a la loza china.

III. Se propone que el salón contiguo al de la loza china, donde ahora se instalan herrajes, se destine a objetos de porcelana, concentrando en este los que existan en otros salones. 


\section{SALON DE MARFILES}

1. El arreglo general de este salón, primero que se instaló retirando objetos de otros, parece adecuado, y, por lo mismo, no hay sugestión que hacer al respecto.

No desconocemos las necesidades financieras del Estado en los momentos anormales por los que atraviesa el pais, pero sí sería de desear que el Gobierno a su digno cargo asignase algunas cantidades con el fin de que cuanto antes se realicen las sugestiones anteriores; con un dispendio de moderada cuantía puede lograrse la mejor conservación de estas piezas. De este modo, cuanto antes, podrá abrir esta institución cultural sus puertas al público; cobrando entonces una modesta cuota de visita, que bien puede ser de 30 o 50 centavos, se irán recabando fondos que permitirán atender muchas de las erogaciones que habrán de hacerse posteriormente.

Interesa pensar que una vez terminada la guerra, el turismo internacional volverá a México y uno de los principales atractivos de la ciudad de Puebla será visitar estas galerías poco conocidas, pero cuya fama ha pasado las fronteras.

Esperamos que el informe anterior oriente a los organizadores del Museo y que éstos sigan contando con el apoyo que hasta este momento el Gobierno no ha escatimado.

\section{Muy atentamente.}

Manuel Toussaint

Manuel Sdnchez Sarto

Justino Fernández
Rafael Garcia Granados

John Mc Andrew

José Miguel Quintana

ANExo 3

Señor Gobernador,

Señor Secretario de Comunicaciones,

Señores y Señozas:

Ha sido diff́cil para mí escoger las sencillas palabras que voy a dirigiros, porque he tenido temor de apartarme de aquellos datos que importan a la historia de la Institución que nace, y entrar a terrenos que, por intimos, no deben traspasar el sagrario de la tradición familiar, ni salir del alma de los que recibimos sangre, nombre y honor del varón cuyo recuerdo va a eternizarse en la casa de cultura y de cariño a 


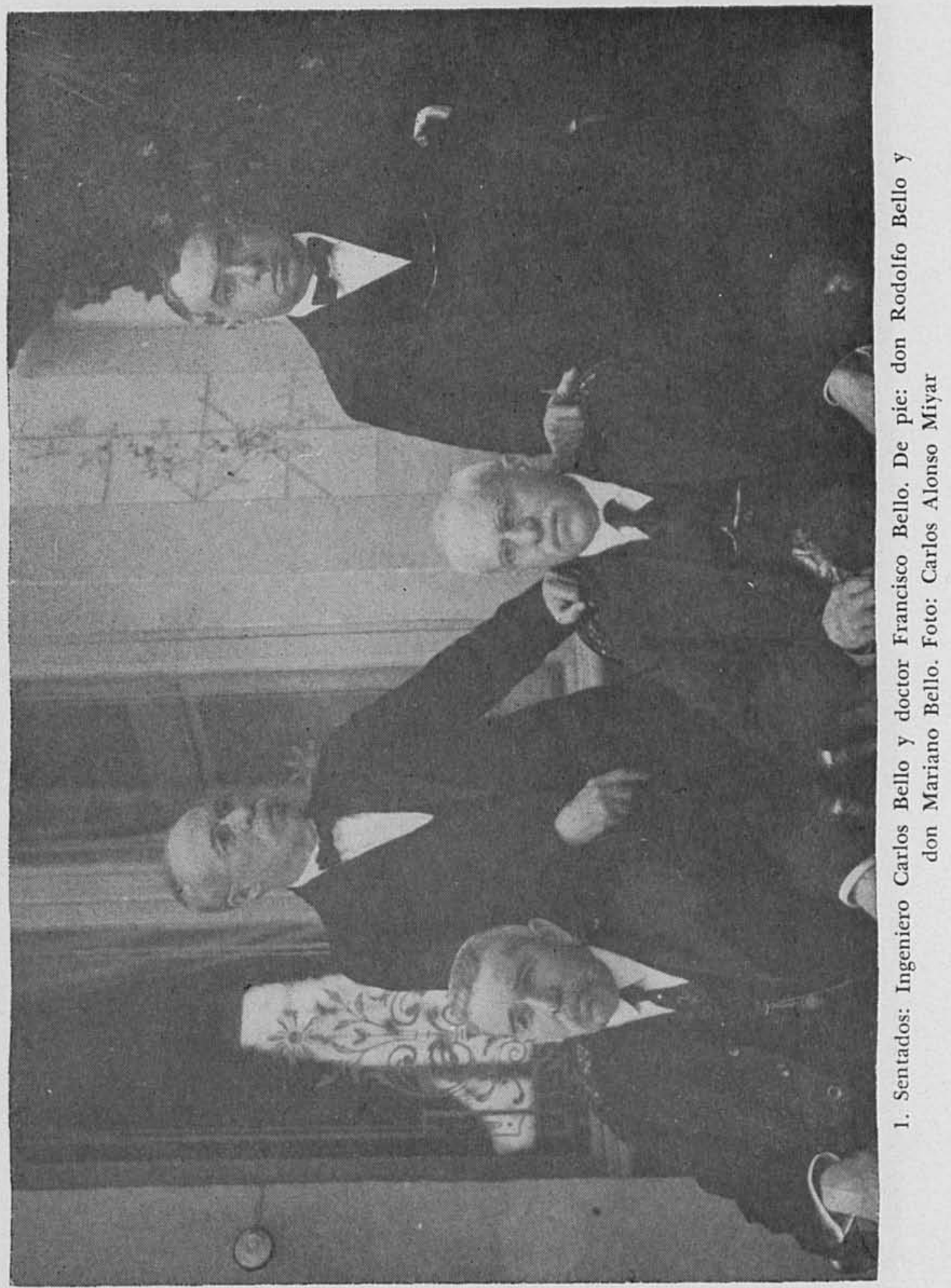




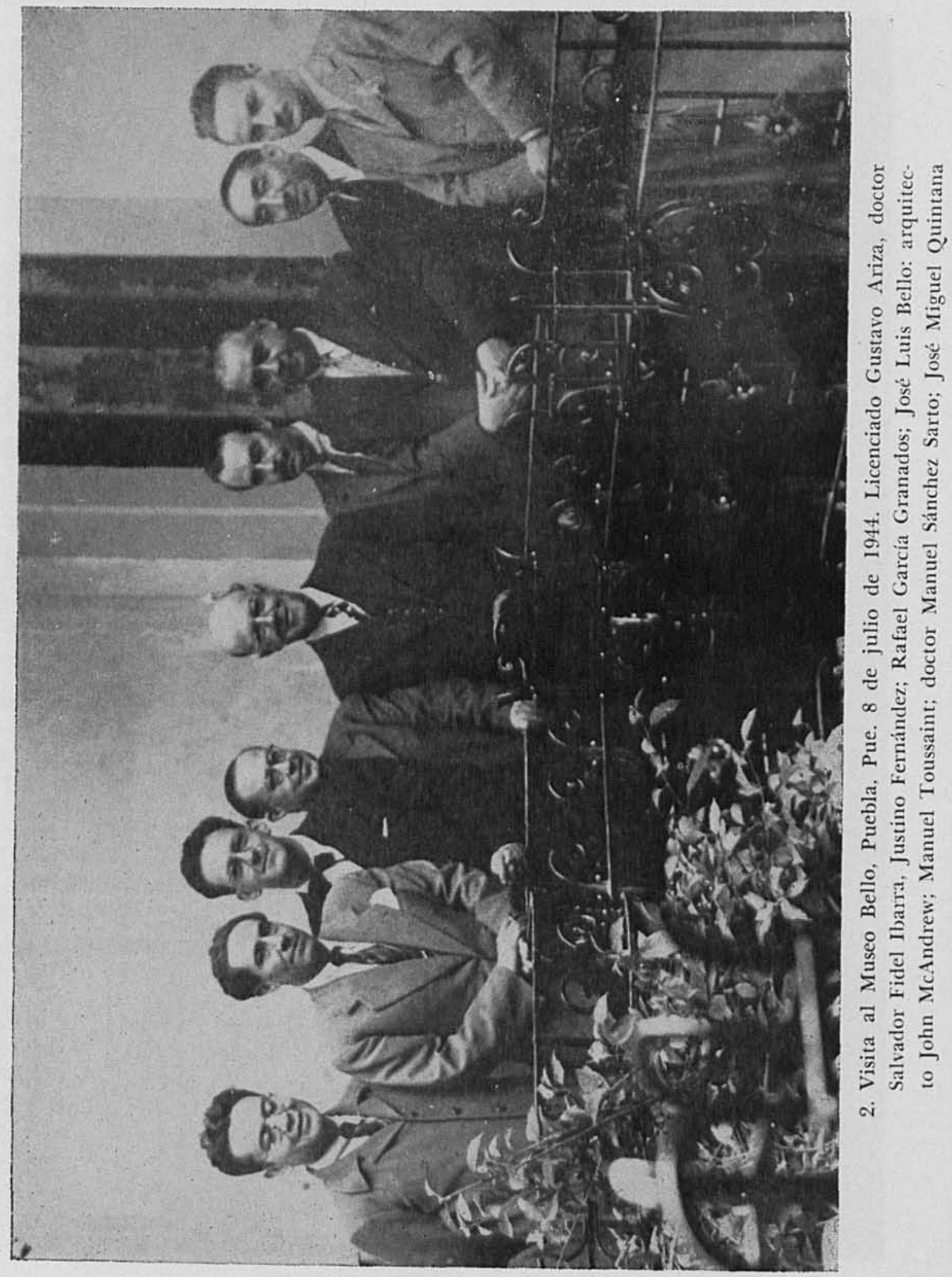


Puebla que empieza a vivir. Si a pesar de mi deseo de reprimir lo que son para mí mi abuelo y mi tío, para relatar sólo sus esfuerzos por conservar y acrecentar el arte original, y que florecio espontáneamente en esta Ciudad, mi narración se vuelve demasiado personal, ruego a mi auditorio que explique y disculpe esta inconsecuencia, que es el resultado de una reverencia afectuosa para el recio y constante ejemplo de virtud que recibí de mis mayores.

Pronto hará un siglo que don José Luis Bello y González, luego que se lo permitieron los medios de fortuna reunidos por una vida de haboriosidad incansable, empezó a reunir objetos de arte, principalmente pinturas, en esta Ciudad. Una cuarta parte de las que coleccionó, aumentada por las obtenidas por su hijo don José Mariano, es la que forma el Museo que se inaugura. $Y$ en el espacio de tiempo que va desde la iniciación del esfuerzo hasta el día en que se incorpora a la vida cultural de Puebla, el concepto del valor de los objetos aquí reunidos ha cambiado radicalmente. Lo que en tiempo de don José Luis Bello y González fue ocupación incomprendida de unos cuantos espíritus selectos, es hoy interés vivo de todos los que sostenemos la capacidad creadora de México, y percibimos en el lenguaje de un arte sin estímulos ni ayudas el mensaje de épocas cuya gloria no consiste en haber logrado éxitos gigantescos y deslumbrantes, sino en haber vencido dificultades enormes, y en haber labrado, en la ruda lucha por vivir, muestras inequivocas de una riqueza espiritual que es la herencia de que la posteridad se siente orgullosa y satisfecha.

En el día en que las colecciones reunidas silenciosamente entre la indiferencia y la incomprensión, se muestran al afán investigador de propios y extraños, es muy grato para mi, en nombre de los descendientes de los que realizaron el esfuerzo humano que aquí cristaliza, traer el recuerdo de las vidas de virtud austera a las que Puebla debe este Museo.

Nació don José Luis Bello y González en el puerto de Veracruz el 19 de agosto de 1822 en el humilde hogar del vista aduanero don José María Bello y doña Carmen González, ambos veracruzanos. Fue el quinto de los nueve hijos de este matrimonio, que no tenia para vivir y progresar más que los sesenta pesos del sueldo paterno. Con la escasa instrucción que pudo adquirir trabajó en su adolescencia como ayudante de vista en la aduana de su ciudad natal. Al ocurrir la invasión norteamericana, cumplió con su deber de mexicano, defendiendo con las armas el suelo patrio, y mereció la medalla "Defensores de la Patria en 1847", de segunda clase. En 1849 se radicó en Oaxaca como empleado en la Casa de Moneda de aquella ciudad. En 1851 se trasladó a Puebla, de donde no debfa salir ya, y se inició en los negocios independientes abriendo, en sociedad con don Francisco Cabrera y Ferrando, una tienda de ropa, con capital de tres mil pesos, que estuvo en la actual casa número 207 de la Calle 2 Norte. El 15 de marzo de 1852 se casó 
en Puebla con doña Francisca Acedo, con quien tuvo 7 hijos: don José Luis, nacido en 1853 y muerto en 1875; don Rodolfo, que nació en 1854 y murió en 1930; don Francisco que nació en 1856 y murió en 1936; don Carlos que nació en 1858 y murió en 1931, dofia Marja del Carmen y doña María Luisa, que murieron en la primera infancia, y don José Mariano, nacido en 1869 y muerto en 1938.

La aptitud y laboriosidad de don José Luis lo hicieron prosperar en sus empresas y su mejoramiento fue aprovechado para cumplir con empeño ejemplar sus deberes familiares. Recogió e incorporó a su familia al quedar viudas a sus hermanas doña Luisa, con seis hijos, a doña Carmen con sus dos hijos, a la viuda de su hermano Mariano, con sus dos hijos, a su hermana Soledad demente, y a una huérfana de la casa paterna. En el año de 1862, al avistarse al ejército francés, se presento al general Zaragoza con sus dos sobrinos don Pedro Millán y Bello y don Manuel Carsolio Bello, que eran los únicos de las personas que vivían con él que estaban en edad de tomar las armas, y que fueron enviados a los cerros, en tanto que a don José Luis se le encomendó la defensa de la trinchera de la Calle de Mesones.

Después del triunfo mexicano, se encargó a don José Luis Bello y González, en unión de don Francisco Díaz Sanciprián la organización de los Hospitales de Sangre y precidió la Junta encargada de reunir fondos para el Ejército de Oriente, encargo en el cual gravó con la cuota más alta su tienda. Tomada Puebla, por el ejército de Forey y junto con su socio y cuñado don Francisco Cabrera, escondieron y ayudaron a evadirse a los generales don Porfirio Dlaz y don Felipe Berriozábal. Durante el Imperio, su esposa fue nombrada dama de honor de la emperatriz y, al declinar el nombramiento, don José Luis manifestó al emperador, con una altivez enteramente republicana: "Que la que era reina y señora de su hogar, no podía ser criada en la casa de nadie."

El 2 de abril de 1867, momentos después de la toma de Puebla, facilitó al general don Porfirio Díaz, cinco mil pesos para el auxilio de las tropas vencedoras, que estaban sin recursos.

Consolidada la República, don José Luis Bello y González se consagró a la naciente industria textil, que iba a ser el nervio de la economía poblana. Fueron suyas las fábricas "La Carolina" y "La Concepción", de Atlixco, y en el trabajo de esas factorias hizo la fortuna que legó a sus hijos. El gobernador Romero Vargas lo llamó a administrar la Beneficiencia Pública, cargo sin sueldo que tenfa una gran importancia social, debido a que las instituciones laicas tenian que llenar el hueco que habian dejado al disolverse las instituciones religiosas. No soblo administró con probidad y acierto los recursos oficiales, sino que se preocupó por reunir con donativos privados elementos que utilizar en la ayuda a los desvalidos. Personalmente se encargó hasta su muerte, y entre otras aportaciones, de dotar de los zarapes necesarios las camas 
del Hospital de San Pedro, y esta costumbre fue continuada por su hijo don José Mariano hasta la extinción del Hospital.

Aunque la limitación del medio en que nació no le permitió adquirir una instrucción variada, fue hombre preocupado por su cultivo espiritual y por el de los seres que formó. De esa aspiración innata y vigorosa en él, de su amistad con los eminentes coleccionistas poblanos don Francisco Díaz Sanciprián, don Alejandro Ruiz Olabarrieta, don Manuel Cardoso y don Luis Suárez Peredo y con los doctores Rafael Lucio y Alfredo Chavero de México, nació su esfuerzo por reunir objetos artísticos que perduró hasta su muerte. Al ocurrir ésta, su Pinacoteca contaba con 250 pinturas y era de primera importancia en Puebla y en la República toda. El afán coleccionista de don José Luis Bello y González fue el más duradero y empeñoso en la Puebla del siglo xix, y a eso se debe que en sus galerfas se reuniera una gran parte de las demás de Puebla. Después de su muerte, acaecida el $1^{\circ}$ de junio de 1907, la colección artística fue dividida en cuatro lotes equivalentes, formados por el distinguido pintor don Daniel Dávila y los entendidos anticuarios, todos poblanos, don Juan Traslosheros Soto y don Ranulfo Carrera y sorteados entre los cuatro hijos de don José Luis que lo sobrevivieron y que fueron don Rodolfo, don Francisco, don Carlos y don José Mariano.

Fue mi abuelo hombre alejado de ostentaciones y vanidades. Jamás aspiró a desempeñar cargos públicos de poder. La Patria contó con él en las horas aciagas en que, desentendiéndose de sus responsabilidades familiares, cumplió el deber de defender el territorio sagrado. Ayudó a las instituciones públicas en la asistencia a los desvalidos, encargo grato a sus convicciones de ciudadano y creyente, fundó y sostuvo centros de trabajo progresista benéficos a su país y formó para el bien y la utilidad social muchos caracteres, que de él recibieron el pan y la orientación a los que todas las contingencias de la vida ha mantenido en el camino del decoro y la probidad, la atracción persistente de su ejemplo. $Y$, además, conservó para lo posteridad un acervo artístico cuyo valor acrecienta el paso del tiempo, y que enseña otro de los ideales que animaron a aquella alma virtuosa: La Familia, La Patria, La Caridad, El Trabajo y El Arte.

La obra de anticuario y coleccionista de don José Mariano Bello y Acedo, es digna de la de su padre. Durante toda su vida continuó reuniendo y conservando con cariño las pruebas de la cultura artística. Incorporó a la colección heredada los cuadros de don Ignacio Arispe Ramos ; los marfiles de don Alejandro Ruiz Olabarrieta, que le cedió la viuda de don Francisco Cabrera y Bello; la porcelana china que fue de don Francisco Cabrera y Ferrando, que vendió la sucesión de doña Manuela Cabrera y Bello, para repartir su precio entre los menesterosos; el magnifico lote de fierros forjados, que fue del distinguido anticuario poblano don Salvador Miranda; los muebles incrustados que fueron de 
la señora Fernández del Valle; el escritorio de carey que perteneció a la' señora Encarnación Ovando de Emmelhainz; los secreteres Luis XV que le vendió doña Lucrecia Lara viuda de Kiera, y los cuadros, cerámicas, porcelanas, muebles, que adquirió en toda su vida.

Es un deber de justicia dedicar un recuerdo de gratitud a los anticua. rios poblanos que ayudaron a don José Mariano a reunir el acervo que alberga este Museo.

Por el empeño de don Vicente M. Rueda, de don Mariano Toquero, de don Juan Traslosheros Soto, de don Enrique Ventosa, de don Ricardo Barreda, de don Vicente Moscoso y de don Francisco Parra y de don Mario Ayala, principalmente, fue posible salvar de la incuria destructora. las preseas de este Museo. Su obra, meritoria y útil, merece que sus nom. bres sean conservados en la historia de esta institución.

La decisión altruista de don José Mariano Bello y el amor a la cultura del gobierno de Puebla permiten que el esfuerzo de dos generaciones rinda su máxima utilidad al abrirse al público este Museo. Los descendientes de sus fundadores sabemos bien que hoy queda cumplida su voluntad, que reunió estas colecciones no por vanidad sino para comprobar la capacidad cultural de esta ciudad, que ellos amaron con fervor, y a cuya gloria contribuye el trabajo paciente, los sacrificios pecuniarios y la lucha contra la indiferencia o la ambición que formaron las colecciones Bello. Es por esto que entre todas las ofrendas de gratitud que recibe el gobierno por la nueva fundación cultural ninguna es más conmovida ni más honda que la que en nombre de todos mis consanguíneos traigo a este recinto.

La aportación de las colecciones Bello al patrimonio cultural de Puebla debe completarse con el catálogo documentado de las colecciones y la historia pormenorizada de las condiciones de ambiente en que se for. maron. Por razones evidentes, es un deber de los descendientes de los fundadores. En esta ocasión, solemne para nosotros, ofrezco que ese deber será cumplido.

Es fuerza terminar aqui. El elogio de los hombres de bien cuyo esfuerzo cristaliza hoy no puede brotar de mis labios. La gratitud conmovida del poblano amante de su terruño se confunde con sentimientos personales intimos y con veneraciones familiares más tiernas. Juzgad vosotros si las vidas que reunieron este Museo son dignas de respeto y de recuerdo. Yo sólo sé deciros, que en el curso de mi vida individual he podido apreciar el valor de muchas de las satisfacciones que nos compensan de los golpes del dolor y de la miseria de nuestra condición, y que no conozco aún ninguna que sea tan intensa, y tan grande como el santo orgullo de llevar su nombre.

VII-21-1944. 
ANexo 4

BIBLIOGRAFía DEL MUSEO beLLO

1. Bello José Luis y Ariza Gustavo,Pinturas poblanas (siglos xvII-xix), México, 1945.

2. Bello José Luis y Cordero y Torres Enrique, Galerias pictóricas de Puebla. Puebla, 1967.

3. Bello José Luis, don José Luis Bello hace grandes aclaraciones, La Opinión, 8 de octubre 1944, Puebla.

4. Dirección de Bienes Nacionales, Secretaría de Hacienda, expediente 210 (724.7) /-18570. Inventario de los objetos de carácter religioso que se entregan al Sr. Mariano Bello (véase anexo 1).

5. Departamento de Impuestos del Timbre y sobre Capitales, Secretaría de Hacienda, expediente 362/162095 y Tribunal Fiscal de la Federación expediente 2077/40, testamento del señor José Mariano Bello.

6. Escandaloso robo de objetos descubierto en el Museo Bello. El Diario de Puebla, 9 noviembre 1944, Puebla.

7. Garcia Granados, Rafael, "Nuestra Ciudad", Excelsior, 20 noviembre 1944, México.

8. Garcia Granados, Rafael, "Nuestra Ciudad", Excelsior, 18 diciembre 1944, México.

9. Grajales, Miguel. Expresa sus puntos de vista D. Miguel Grajales; La Opinión, octubre 7 de 1944, Puebla.

10. Grajales, Miguel, don Miguel Grajales hace una aclaración que es pertinente; La Opinión, 21 junio 1944, Puebla.

11. Grajales, Miguel. El señor Miguel Grajales hace una pertinente y justa aclaración; La Opinión, 5 agosto 1944, Puebla.

12. Ibarra, Dr. Salvador Fidel, "Las pinturas del Museo Bello." Revista Vida, núm. 13, julio 1959, Puebla.

13. Investigan la desaparición de unos objetos artísticos del Museo Bello; La Opinión, 6 octubre de 1944, Puebla.

14. "La prestigiosa talavera de Puebla", Revista de Revistas, 23 de agosto 1925, México.

15. León de la Barra, Luis, "Un nuevo Museo", Excelsior, 23 de marzo de 1945, México.

16. Levi Peza, Cap. Manuel, "Mirada al Museo Bello", Suplemento de El Sol de Puebla, 18 de agosto 1957. Puebla.

17. Mendoza, Moisés, Cosas de Provincia. "El Museo Bello de Puebla", El Nacional, 10 de febrero de 1940, México. 
18. Periódico Oficial del Estado de Puebla, de 28 de marzo de 1944, Puebla.

19. Quintana, José Miguel, "La Colección de don Mariano Bello", Revista Hoy, núm. 38, noviembre 13 de 1937, México.

20. Salazar Monroy, Meliton, Museo Bello, Puebla, 1945.

2I. Salazar Monroy, Meliton, El Museo Bello y sus tesoros artisticos, Puebla, 1946.

22. Salazar Monroy, Meliton, Bello's Museum in Puebla, Puebla, 1948.

23. "Se abrirá el Museo de Bello", Excelsior, 27 febrero 1943, México.

24. Valle, Rafael Heliodoro (Lic, Vidriera), "Cosmópolis", Excelsior, 19 de abril 1944, México.

25. Valle, Rafael Heliodoro (Lic. Vidriera), "Cosmópolis", Excelsior, 2 agosto 1944, México.

26. Valle, Rafael Heliodoro, "Don Marianito Bello y su estupenda colección", Jueves de Excelsior, México, 16 septiembre 1937. 